\title{
CURRÍCULO DE LICENCIATURA EM QUÍMICA DA UNIVERSIDADE DE BRASÍLIA: UMA PROPOSTA EM IMPLANTAÇÃO
}

Wildson Luiz P. dos Santos, Ricardo Gauche e Roberto Ribeiro da Silva

Departamento de Química - Universidade de Brasília - 70.910-900 - Brasília - DF

Recebido em 10/10/96; aceito em 25/4/97

\begin{abstract}
A NEW CURRICULUM LEADING TO THE FORMATION OF A LICENCIATE IN CHEMISTRY AT THE UNIVERSITY OF BRASÍLIA. This article presents the conception, principles and academic structure of the evening course leading to the formation of a Licentiate in Chemistry, at the University of Brasília. The curriculum has been carried out since the beginning of 1993. This curriculum has as its basic axis the graduation of future teachers integrated with the conceptual formation in Chemistry. Interdisciplinary actions are planned between the Chemistry Department, the Psychology Institute and the Faculty of Education so as to provide mechanisms which would allow the licenciate to acquire teaching experience along the course.
\end{abstract}

Keywords: chemistry teachers; undergraduate curriculum; evening courses.

O currículo do curso noturno de Licenciatura em Química da Universidade de Brasília (UnB) teve origem com a criação dos cursos noturnos de licenciatura no âmbito da universidade como um todo, ocorrida no segundo semestre de 1992. A primeira turma ingressou no primeiro semestre de 1993.

No processo de criação, foi constituída uma comissão, com representantes das setes unidades acadêmicas dos cursos que foram criados, com a função de elaborar o Projeto Acadêmico Orgânico para os Cursos Noturnos de Licenciatura. A partir dos princípios estabelecidos naquele projeto, começou-se a delinear a estrutura do currículo atual.

A discussão do currículo de química envolveu diretamente todos os professores do Departamento de Química que trabalhavam no noturno em 1993 e 1994. Além destes, vários professores do diurno colaboraram na definição de disciplinas dentro de áreas específicas do conhecimento. Tendo por base as sugestões apresentadas pelos professores, o desempenho dos alunos que já faziam o curso e a experiência de profissionais de outras universidades, ligados à formação de professores de química, foram sendo construídos e testados os princípios estruturais do currículo até o segundo semestre de 1995, quando, então, este foi aprovado pelo Conselho de Ensino, Pesquisa e Extensão da Universidade de Brasília.

Para a elaboração da estrutura curricular que foi construída ao longo dos três anos iniciais de implantação do curso, foram estabelecidos pressupostos curriculares que fundamentaram o desenvolvimento do currículo ora aprovado. Tais pressupostos, que são apresentados mais adiante, tiveram como princípio básico a identidade do curso, tanto na sua natureza de formação de professores, quanto na sua peculiaridade de funcionar no turno noturno.

Desde o início da criação dos cursos noturnos de licenciatura na Universidade de Brasília, procurou-se construir um currículo comprometido com a formação de cidadãos capazes de participar do processo de transformação da sociedade brasileira. Tal orientação, na verdade, alinhava-se à própria pressão social que justificou a implantação daqueles cursos, na medida em que uma antiga reivindicação da sociedade, expressada por várias organizações civis, exigia da universidade tempo e espaço para suprir algumas de suas necessidades, dentre as quais inscreviam-se os cursos noturnos.

Sendo assim, adotou-se, como justificativa para a criação do curso noturno de Licenciatura em Química, a própria carência de professores da área, gerando graves problemas no suprimento da demanda escolar. Nesse sentido, entendemos que atender aqueles anseios sociais, de ocupar espaço e tempo ociosos de uma universidade pública e, portanto, comprometida com a sociedade que a sustenta e lhe dá razão de existir, era acima de tudo propiciar um curso que viesse superar as suas exigências.

Foi dessa forma que concebeu-se como eixo organizativo da proposta curricular a caracterização específica de curso noturno com vistas à formação de professores de Química. Isso significa que o currículo proposto visa atender às peculiaridades de um curso noturno e às exigências para a formação do professor de Química.

\section{DA IDENTIDADE DO CURSO}

Acreditamos na necessidade de conceber um currículo que leve em consideração as condições do curso noturno, pois defendemos o princípio, estabelecido no Projeto Acadêmico Orgânico para os Cursos Noturnos de Licenciatura da $\mathrm{UnB}^{1}$, de que:

"Uma instituição educacional que não toma conhecimento dos caracteres e condições dos seus estudantes começa por negar a sua própria identidade e trair sua missão. Não há como sustentar a indiferenciação do corpo discente dos dois turnos. E o reconhecimento das diferenças, para ser conseqüente, não pode deixar de admitir distinções que vão do ritmo dos cursos à sua duração; da reconstrução das grades curriculares 'a metodologia dos inter-relacionamentos intersubjetivos. Não se trata, todavia, de minimizar os componentes curriculares e sim de compatibilizá-los às condições dos estudantes, atribuindo-lhes eficácia e propriedade." (p. 10)

Além disso, estabelecemos o princípio da busca da identidade do curso de licenciatura, porque, tradicionalmente, os currículos restringem-se a ser meros apêndices dos currículos de bacharelado. Tal fato tem sido detectado por pesquisas de avaliação diagnóstica de cursos de licenciatura. Segundo catalogação de Candau ${ }^{2}$, um dos principais problemas destes cursos refere-se à falta de integração entre teoria e prática. Em geral, os currículos de licenciatura correspondem a currículos de bacharelado com complementação final em disciplinas psicopedagógicas. Isto tem caracterizado a licenciatura como curso apendicular e tem ocasionado a desarticulação entre as disciplinas ditas de conteúdo específico em Química e as disciplinas chamadas de psicopedagógicas.

A concepção do curso de licenciatura aqui apresentada é, indiscutivelmente, distinto da referente ao curso de bacharelado. 
Logo, ele não será, como propõem ingenuamente alguns, similar ao bacharelado, se tornando um seu apêndice. Decorre dessa visão limitada que a similitude dos currículos do bacharelado e licenciatura garantiria a "qualidade" na competência técnica do professor. Deve-se considerar que as disciplinas de química do curso de bacharelado é desvinculada da parte pedagógica e voltada, na maioria das vezes, para a pós-graduação nas áreas tradicionais da Química ou para o trabalho industrial, desprezando a importante abordagem epistemológica. Portanto, ledo engano é imaginar que a reprodução direta das disciplinas do bacharelado seria exigência para garantir o conhecimento específico em Química para o licenciando. Essa equivocada opinião felizmente já não encontra eco na pesquisa sobre a formação do professor-educador (Candau ${ }^{2}$, Gil-Pérez \& Carvalho $^{3}$ ).

Não se discute, obviamente, a necessidade de se propiciar aos licenciados uma formação densa e profunda em Química. Entretanto, há que se compreender a natureza específica do curso voltado para a formação de profissional que, além de dominar tecnicamente o conteúdo, deve ter a competência inerente ao processo educacional, caracterizado por relações complexas que transcendem o conhecimento específico da disciplina envolvida, abarcando aspectos de ordem psicológica, pedagógica, sociológica, filosófica, etc.(Gil-Pérez \& Carvalho ${ }^{3}$ ).

Nesse sentido, procurou-se delinear um currículo para o curso noturno de Licenciatura em Química que não representasse um mero reflexo ou adaptação do currículo adotado no curso diurno. Logo, ele não é como a maioria das licenciaturas tradicionalmente estruturadas. Ele tem uma identidade própria: É UM CURSO DE FORMAÇÃO DE PROFESSORES DE QUÍMICA!

\section{DOS PRINCÍPIOS CURRICULARES ESTABELECIDOS}

\section{a) Formação Profissional Docente como eixo gerador}

Profissionalizar o aluno no curso de licenciatura é prepará-lo para o exercício do magistério. Obviamente essa preparação deve se dar no âmbito de todas as disciplinas do curso. Todavia, há algumas que contribuem de maneira direta no desenvolvimento de potencialidades específicas para a prática pedagógica. Tais disciplinas constituem a área que foi denominada no Projeto Acadêmico Orgânico como de Formação Profissional Docente (FPD), configurando-se como

“...um espaço curricular caracterizado pela intenção de chegar à interdisciplinaridade a partir da convergência recíproca das três vertentes (a psicológica, a pedagógica e a que distingue cada licenciatura) que contribuem à formação do professor. Nele, o endereçamento ao ensino, de todas as disciplinas que o compõem, constitui a sua unidade, na diversidade das contribuições específicas que para o ensino concorrem."1 (p.23)

Cabe ressaltar que a formação profissional docente não se dará exclusivamente pela existência de disciplinas específicas do curso e outras de natureza pedagógica e psicológica, mas sobretudo pela integração dessas disciplinas em abordagem interdisciplinar. Interdisciplinaridade essa que deve envolver todas as demais disciplinas do curso ${ }^{1}$.

Sendo assim, as disciplinas oferecidas pelo Instituto de Psicologia e pela Faculdade de Educação "assumem o sentido preparatório da competência do professor para dar suporte ao desenvolvimento pessoal, mediante a área de conhecimento que lhe é específica" (Pinto ${ }^{1}$, p. 23). Após essa fase preparatória, o aluno consolidará sua formação nas disciplinas específicas da área de ensino de química. A área de formação profissional docente corresponde, no presente currículo, a cerca de vinte e cinco porcento do total dos créditos do curso.

Além disso, concebe-se que a profissionalização dar-se-á, também, por meio de medidas que propiciem ao aluno a vivência de experiências concretas no exercício do magistério, dentro da rede escolar. Segundo Linhares ${ }^{4}$, a formação do professor pressupõe a necessidade do licenciado conhecer a realidade da escola pública e de seus alunos. Moreira ${ }^{5}$ destaca também que os professores estão despreparados para lidar com alunos das classes populares, sobretudo devido ao seu desconhecimento da realidade social das mesmas. Portanto, propiciar oportunidades aos licenciados de ter o maior contato possível com a realidade escolar e, ao mesmo tempo, permitir reflexões sobre a realidade, é favorecer condições para superar as deficiências apontadas por esses autores.

\section{b) Consolidação da Formação Profissional Docente na área de Ensino de Química}

Buscar atender à especificidade do curso na formação do professor de Química é conceber uma estrutura curricular que leve em conta as exigências profissionais do futuro professor. Sendo assim, os alunos necessitam da formação em conteúdo específico, que os habilite ao exercício do magistério, bem como o desenvolvimento da competência inerente ao processo educacional. Por isso, não se pode desvincular a formação em conteúdo da formação psicopedagógica, situando-as em momentos distintos. Essas devem ocorrer de maneira concomitante ao longo do curso, de forma que o aluno correlacione as variáveis relacionadas ao ensino-aprendizagem dos conceitos com sua própria aprendizagem. Nesse processo, as disciplinas da área de Metodologia de Ensino de Química desempenham um papel central $\left(\right.$ Gil-Pérez \& Carvalho $^{3}$ e Astolfi \& Develay ${ }^{6}$ ). Pretende-se, assim, superar os obstáculos de muitos currículos de licenciatura, em que há um completo distanciamento entre a teoria e a prática.

Cabe à área de Metodologia de Ensino de Química favorecer a síntese integradora entre os conceitos e os princípios metodológicos. Essa síntese se dá, sobretudo, por meio de pesquisas específicas sobre o processo de ensino-aprendizagem dos conceitos químicos. Sendo assim, essa área, pela sua natureza, contribuirá decisivamente para a efetivação da função da Universidade nos seus aspectos de ensino, pesquisa e extensão. Nesse sentido, a Metodologia de Ensino tem um papel integrador de revitalizar o curso, favorecendo sua inserção no seu legítimo espaço na universidade. Isso significa fazer com que a licenciatura deixe de ser um curso apendicular, passando a ter identidade própria.

Por outro lado, conforme propõe Moreira ${ }^{7}$, Astolfi e Develay $^{6}$ e Gil-Pérez e Carvalho ${ }^{3}$, a formação do professor de ciências deve incorporar o desenvolvimento de habilidades para a realização de pesquisas educacionais. Segundo Moreira ${ }^{7}$, é essencial que se tenha um professor-pesquisador, pois o mesmo poderá desenvolver postura crítica em relação ao seu ensino, estando aberto às necessárias mudanças do processo, conforme demonstrarem os resultados das pesquisas. Sendo assim, caberá também à área de Metodologia de Ensino de Química favorecer a formação do professor-pesquisador, na medida que envolver os licenciandos em pesquisas educacionais (Gil-Pérez \& Carvalho $^{3}$ ).

\section{c) Adoção de práticas pedagógicas que desenvolvam uma concepção de ensino apropriada à formação do licenciando}

De um modo geral, o que se observa é que o professor reproduz a prática de sala de aula que ele vivenciou na sua formação $\left(\right.$ Gauche $^{8}$, Santos $\left.{ }^{9}\right)$. Além disso, o estilo de ensino que o professor do ensino médio utiliza manifesta a sua concepção de ensino-aprendizagem (Harley \& Osborne ${ }^{10}$ ). Assim é que os cursos, cujas disciplinas são ministradas de forma autoritária, sem espaço para a discussão e participação ativa dos alunos, consolida nesses uma concepção de ensino por transmissão, centrada no professor. Tal concepção distancia-se daquela que se pretende desenvolver em nossos licenciados. 
Concretizar a formação pedagógica dos licenciados significa, também, buscar o estabelecimento de procedimentos de ensino favoráveis à aprendizagem nas disciplinas de conteúdo de Química. Isto porque como demonstra Pimenta ${ }^{11}$, os professores dessas disciplinas servem de modelo pedagógico para o futuro professor. Sendo assim, torna-se necessária a adoção de procedimentos que viabilizem a consolidação, em sala de aula, por parte de todos os professores do conteúdo específico de química, de uma postura de ensino que reflita a concepção de ensino-aprendizagem que se pretende formar nos licenciandos.

Para isso, o presente currículo estabelece ações que visam favorecer o planejamento participativo, a troca de experiência pedagógica e a discussão de princípios gerais de metodologia de ensino entre todos os professores do Departamento de Química que ministram disciplinas na licenciatura noturna. Esse planejamento participativo é uma forma de articulação coletiva do currículo em construção (Alves e Garcia ${ }^{12}$ ), permitindo aos professores participação efetiva na implantação do currículo, ao contrário do que acontece em muitos cursos, em que a maioria dos professores é desinformada quanto à estrutura dos currículos de graduação (Morosini ${ }^{13}$ ).

Além disso, conforme salienta Tunes ${ }^{14}$,

“(...) aprender o conceito de átomo para resolver um problema de química, por exemplo, é diferente de aprender o mesmo conceito para ensiná-lo: são duas ações com diferentes finalidades que implicam, por sua vez, diferentes definições da situação e distintas operações analíticas. No exercício da profissão, alguns professores acabam por perceber que há problemas quando se separa conteúdo de método de ensinar, embora, muitas vezes, não consigam encontrar os caminhos para solucioná-lo” (p. 44).

Tudo isso implica na necessidade de discutir metodologias de ensino de graduação que sejam adequadas à formação de professores.

\section{d) Consolidação da formação dos conceitos químicos}

A formação do professor pressupõe obviamente, a necessidade do conhecimento dos conceitos da disciplina a ser lecionada. Por outro lado, fornecer ao futuro professor uma base sólida de conteúdo implica na sua seleção e abordagem em um nível de profundidade que atenda às necessidades futuras desse profissional. Fornecer um conteúdo neutro, estanque, descontextualizado da área de atuação profissional é não dar sentido para a sua essencialidade, o que significa a sua desvalorização, ou melhor, a sua negação.

Nesse sentido, o conteúdo químico que deve ser de domínio do futuro professor é aquele que dê uma visão ampla da Química, mas que inclua os conceitos inseridos no âmbito do ensino fundamental e médio. Cabe ressaltar que as disciplinas de conteúdo específico, quando não dão ênfase nos conceitos básicos, podem perder a sua essencialidade, ficando em emaranhados conceituais distanciados dos conceitos básicos que constituirão as ferramentas do futuro professor.

Por outro lado, o baixo rendimento evidenciado nos cursos de graduação de Química indicam que muito provavelmente os estudantes não estão dominando os atributos conceituais básicos do conteúdo químico. Pode-se atribuir como uma possível causa para esse baixo rendimento o fato de que, em função da extensão dos conteúdos das disciplinas de Química, os conceitos, em geral, são abordados superficialmente sem o estabelecimento adequado de relações de idéias que permita a sua aprendizagem significativa.

Segundo Ausubel, para que ocorra aprendizagem significativa é essencial que as informações a serem adquiridas sejam abordadas por meio do relacionamento de idéias com a estrutura cognitiva do aluno, de maneira substantiva e não arbitrária (Ausubel ${ }^{15}$ ). Isso significa que, sem uma abordagem metodológica do conteúdo que leve em conta aspectos cognitivos e a ordenação das idéias, o aluno realizará uma aprendizagem mecânica. Essa é caracterizada pela interação arbitrária entre o conhecimento e as idéias pré-existentes dos sujeitos, de forma que não possua significado dentro da estrutura cognitiva do indivíduo.

Sendo assim, é fundamental que os conteúdos de Química sejam abordados de maneira adequada, que propicie a aprendizagem significativa. Portanto, não basta que o mesmo seja extensivamente abordado nas disciplinas específicas, mas que, sobretudo, seja aprendido significativamente pelos estudantes. Além disso, a abordagem metodológica do ensino destes conteúdos deverá levar em conta, principalmente, o objetivo de preparar o futuro professor para ser capaz de aprofundar os conhecimentos e buscar a aquisição de novos.

\section{e) Formação em Ciência-Tecnologia-Sociedade}

É essencial que a formação do licenciando seja ampla, de modo a proporcionar-lhe uma visão geral do conhecimento químico e de suas interfaces. Essa visão, segundo Gil Pérez e Carvalho $^{3}$, vai muito além do que tradicionalmente é ministrado nos cursos universitários, englobando aspectos relativos à epistemologia da ciência, às interações ciência-tecnologia-sociedade e às interações entre os diferentes campos do conhecimento de matérias afins. Tal conhecimento deve, ainda, segundo esses autores, propiciar ao licenciando realizar a seleção adequada dos conteúdos que forneçam aos seus futuros alunos uma visão de ciência como processo social de construção do conhecimento e que sejam acessíveis e suscetíveis de produzir neles o devido interesse.

Tal conhecimento da interface ciência-tecnologia-sociedade tem sido atualmente proposto em currículos de educação básica, de graduação e pós-graduação em cursos de ciências do mundo inteiro (Bybee \& $\mathrm{Mau}^{16}$; Fensham ${ }^{17}$ ). Essas propostas curriculares, conhecidas como movimento de ensino de CTS (ciência-tecnologia-sociedade), têm apresentado como principal objetivo a formação da cidadania, por intermédio do desenvolvimento da capacidade de tomada de decisão por parte do aluno $\left(\right.$ Santos $\left.^{18}\right)$

Considerando que o principal objetivo da educação básica é a formação da cidadania, verifica-se que para a consecução deste objetivo é fundamental a inclusão, no currículo, de conhecimentos da interface CTS. Por isto, é fundamental que o presente currículo aborde fatores sócio-econômicos, políticos, culturais e históricos relativos à tecnologia.

\section{f) Currículo em constante processo de construção}

Considerando que tanto o conhecimento como a aprendizagem se configuram como processos em construção e que o modelo de ensino que se pretende desenvolver com os licenciandos baseia-se em pressupostos construtivistas, torna-se necessário que as disciplinas do curso espelhem essa concepção. Assim, propõe-se que o planejamento das disciplinas ocorra de forma flexível, de modo a incorporar as novas proposições da sua área de conhecimento, advindas da pesquisa científica, bem como permitir que sejam levados em conta os conhecimentos prévios dos alunos.

Neste contexto, obviamente não cabem os programas assentados em uma estrutura rígida de organização curricular baseada nos compêndios tradicionais da área de conhecimento. Tais programas, que se repetem ao longo de décadas nos diversos cursos universitários, na maioria das vezes, só são atualizados após vários anos de mudança conceitual na própria área. Além disso, os planos de ensino que apresentam um cronograma rígido de desenvolvimento não propiciam, pela sua natureza, a necessária consideração do processo dinâmico da construção do conhecimento pelo aluno, o qual não ocorre de maneira linear e cartesiana, como espelham os referidos planos de ensino.

Além de prever a flexibilidade de planejamento das disciplinas, pretende-se que o presente currículo seja suficientemente 
dinâmico para evitar que se torne engessado em si mesmo. Sendo assim, deseja-se que este projeto configure-se em proposta curricular para ser vivenciada e avaliada no decorrer dos próximos anos. Ele deve estar aberto a modificações que permitam o crescimento do curso e o atendimento às novas necessidades que surgirão no decorrer do tempo.

\section{DAS ESTRATÉGIAS PARA IMPLEMENTAÇÃO DO CURRÍCULO}

Para garantir os princípios estabelecidos, foram adotadas diversas ações, das quais podem-se destacar as enumeradas a seguir.

\section{a) Realização de Seminários Pedagógicos e de cursos na área de Metodologia do Ensino Superior}

Considerando que o currículo não corresponde à enumeração simples do elenco de disciplinas, mas ao desenvolvimento efetivo de todas as atividades de ensino das quais o aluno participa durante o seu curso, percebe-se que a implantação do currículo regula um estudo profundo sobre a metodologia de ensino de cada disciplina e o desencadeamento de um processo contínuo de avaliação e redimensionamento de atividades. Com base nestes estudos são propostas a adoção de alternativas pedagógicas que atendam às necessidades dos alunos do noturno. É assim que, em conjunto, podem-se encontrar propostas de ensino que não seja exclusivamente preletivo e presencial.

É esta a razão que motivou a organização de seminários pedagógicos. Nesses seminários, todos os professores do curso noturno do Departamento de Química tem a oportunidade de discutir e avaliar o ensino desenvolvido na sua disciplina, bem como estabelecer procedimentos didáticos conjuntos que favoreçam a formação do licenciando. A avaliação da aprendizagem tem sido motivo constante de análise, tendo em vista tradicionalmente se constituir em "reprodução de conhecimentos transmitidos", o que exige o planejamento de formas alternativas que priorizem a compreensão e a inter-relação conceitual na resolução de problemas. Tais reuniões permitem, ainda, a integração entre as disciplinas do curso e o estudo dos princípios orientadores do currículo, incluindo temas relacionados à formação de professores, à metodologia de ensino e ao conteúdo específico de Química.

Considera-se que sem a garantia deste espaço de planejamento participativo a filosofia proposta para o currículo de licenciatura perde a sua unidade de princípios e comete-se o erro do isolamento acadêmico e da desarticulação. Essa experiência já vem sendo adotada com sucesso, desde o primeiro semestre de 1994, tendo-se, inclusive, conseguido efetivar a elaboração do presente currículo.

Também já foram realizadas algumas avaliações, por meio de questionários respondidos pelos alunos. Estas apontam a existência de clima extremamente positivo no relacionamento professor-aluno que tem favorecido a aprendizagem. Acreditase que os seminários estejam favorecendo o desenvolvimento desse aspecto.

\section{b) Redimensionamento de disciplinas introdutórias}

Inicia-se o fluxo com a disciplina "Introdução ao Estudo da Química”, a qual busca cumprir o papel explicitado no Projeto Acadêmico Orgânico de articulação dos novos conhecimentos aos quais o aluno será exposto com sua experiência escolar anterior (Pinto ${ }^{1}$, p. 19). Tem-se buscado, no desenvolvimento dessa disciplina, a vivência de prática pedagógica que leve em conta a adoção de princípios metodológicos de construção de conceitos, por meio de atividades experimentais de investigação.
Tal disciplina introdutória dá ênfase à formação de conceitos básicos de Química, à caracterização epistemológica da Química, à preparação do aluno para as suas tarefas acadêmicas, incluindo técnicas de estudo, e à conscientização da formação para o exercício do magistério. Portanto, não tem sido ministrada nos moldes dos tradicionais cursos introdutórios do chamado ciclo básico, caracterizados por um denso conteúdo. Pretende-se com a citada disciplina fazer com que "a experiência inicial de um estudante universitário não seja negligente ou massacrante $e$ não se prolongue a crença de que o massacre é intrinsecamente educativo, pois faria estudar" (Pinto ${ }^{1}$, p. 21).

Assim, o extenso conteúdo programático dos tradicionais livros de "Química Geral" não foi incorporado a uma única disciplina, mas redistribuído e redimensionado entre a disciplina Introdução ao Estudo da Química e as disciplinas iniciais de cada área da química. Propôs-se, então, que nas áreas de Química Inorgânica, Analítica e Orgânica houvesse uma disciplina de caráter introdutório, denominada de "Fundamentos de (respectiva área)". Essas disciplinas têm o papel de introduzir o aluno na área, abordando os conteúdos fundamentais para o seu estudo, atribuindo-lhe sentido epistemológico e função para o ensino. Com tal procedimento evita-se que uma disciplina introdutória tenha um conteúdo extenso que seria repetido posteriormente.

\section{c) Redimensionamento das disciplinas de conteúdo de química}

A formação conceitual do professor de química, conforme os parâmetros estabelecidos nos pressupostos curriculares, ocorrerá no âmbito das disciplinas de Química Inorgânica, Química Analítica, Química Orgânica e Físico-Química. Em Química Inorgânica, o aluno cursa três disciplinas obrigatórias, "Fundamentos de Química Inorgânica", "Química dos Elementos Representativos" e "Química de Coordenação"; em Química Analítica, quatro disciplinas, "Fundamentos de Química Analítica", "Análise Química Qualitativa", "Análise Quantitativa" e "Fundamentos de Análise Instrumental”; em Química Orgânica, três, "Fundamentos de Química Orgânica", "Reações Orgânicas e seus Mecanismos" e "Laboratório de Química Orgânica"; e finalmente em Físico-Química, quatro disciplinas, "Termodinâmica Básica", "Equilíbrio Químico e Soluções", "Estruturas de Átomos e Moléculas e Cinética Química" e "Laboratório de Físico-Química".

Para que tais disciplinas possam atender às exigências da formação do licenciado dentro do perfil esperado do futuro professor, bem como as peculiaridades do curso noturno, foi necessário estabelecer ementas diferenciadas das disciplinas correspondentes do diurno. De início, estabeleceram-se, para as mesmas, nomes distintos dos que nomeiam as disciplinas do diurno. A nova denominação das disciplinas foi adotada de forma a caracterizar o seu conteúdo, fugindo da antiga tradição de nomear disciplinas por números que não identificam claramente a sua natureza, como por exemplo a denominação Química Inorgânica I, Química Inorgânica II, etc.

Considerando, ainda, que o professor deve ter uma visão a mais ampla possível da sua área de conhecimento para que possa buscar a essencialidade do conteúdo necessário aos alunos, bem como possa analisar as aplicações tecnológicas e implicações sociais do conhecimento, foram incluídos nos ementários conteúdos relativos a conhecimentos da área de interface em CTS, englobando aspectos históricos e ambientais. Além disso, foram acrescentadas no currículo disciplinas que complementam a formação do licenciando e que se situam em áreas de interface da Química: "Introdução à Tecnologia Química", da área tecnológica; "Evolução dos Conceitos da Química", da área de História da Química e "Tópicos de Química Ambiental", da área de Química Ambiental. 
d) Formação através da prática de ensino, integrando teoria e prática

Visando superar o distanciamento entre as propostas metodológicas discutidas na Universidade e a realidade concreta de sala de aula que o futuro professor vai enfrentar, propõe-se que todas as disciplinas da área de formação profissional docente (FPD) incluam atividades que visem a observação in loco de situações concretas de ensino escolar. Tais atividades podem ser observações, pesquisas de campo - por meio de entrevistas, filmagens etc. - ou, ainda, palestras, seminários e minicursos ministrados nas escolas pelos licenciandos.

Essas atividades têm como objetivo o conhecimento da realidade educacional, o preparo do licenciando para realizar pesquisas educacionais e a formação do professor, por meio da prática pedagógica. Para tanto, propõe-se que tais atividades sejam planejadas entre os professores das disciplinas de FPD, de forma que sejam desenvolvidas de maneira gradual e integrada, propiciando a formação do professor-pesquisador e a atitude crítica de reflexão sobre a prática pedagógica. Sendo assim, espera-se que tais tarefas não sejam realizadas mecanicamente com o único intuito de satisfazer uma exigência curricular para obtenção de nota. Ao contrário, essas atividades deverão ser inseridas em um processo formativo, por meio da prática concreta.

Esse procedimento fará com que o contato do licenciando com a escola seja efetivado durante todo o curso e não apenas no estágio supervisionado. Isto de certa forma propiciará a formação do professor por meio da sua prática. Dessa forma, os pressupostos teóricos a serem abordados nas disciplinas de FPD poderão ser confrontados e examinados à luz de uma prática que poderá ser construída ao longo do curso.

Neste sentido, para que a formação do professor seja de fato desenvolvida gradualmente, as disciplinas de FPD foram distribuídas ao longo de todo o fluxo do curso, de forma que em todos os semestres exista, pelo menos, uma disciplina desta área. Entende-se assim superar o modelo tradicional dos cursos de licenciatura em que a formação psicopedagógica só ocorre no final do curso, de maneira distanciada da prática do professor. Além do que, nestes currículos, o estágio supervisionado constitui praticamente o único contato direto do licenciando com a escola, feito após as disciplinas pedagógicas, sem que haja espaço para reflexão crítica da prática vivenciada.

Para superar tal problemática, foi incluída no quinto semestre do curso a disciplina "Prática de Ensino de Química". Essa disciplina, de natureza prática, tem como objetivo a vivência de situações concretas de magistério pelo licenciando, por meio de diferentes modalidades, tais como minicursos, ofertados para alunos do ensino médio ou da própria Universidade; aulas de recuperação no ensino regular; ou, ainda, aulas de laboratório de Química para alunos do ensino fundamental e médio. Tais experiências propiciam o início da prática de ensino, que é objeto de análise pelo professor da disciplina e demais colegas, que assistem às aulas. Isso permite, também, que o aluno possa refletir a prática vivenciada durante o estudo das demais disciplinas da formação profissional docente, buscando sempre a integração teoria-prática.

Outra modalidade de atividade dessa disciplina é o trabalho de análise e reflexão sobre a prática pedagógica do licenciando que já está no exercício do magistério. Tal fato é comum, mesmo com alunos no início de curso, em função da falta de professores de química no Distrito Federal. Ainda nessa disciplina, os licenciandos são envolvidos em projetos de pesquisa e de extensão desenvolvidos em escolas, ou na Universidade, propiciando aos mesmos experiências inovadoras na rede de ensino.

Ainda com a concepção de consolidar a formação crítica do professor, por meio da reflexão de sua própria prática pedagógica, propõe-se a realização do estágio ao final do curso em regime de regência em sala, com supervisão de professores da área de ensino de química, de professores do Instituto de Psicologia e da Faculdade de Educação. Sendo assim, o estágio será oferecido pelo Departamento de Química, tendo a co-participação de três professores, os quais farão um trabalho interdisciplinar de orientação conjunta ao estagiário. Essa é uma inovação no presente currículo, uma vez que concretiza, em um espaço institucional, o trabalho interdisciplinar. A reflexão do processo educativo será desenvolvida com enfoque no ensino específico de Química, analisando-se os seus condicionantes de natureza psicológica e de organização e estrutura do sistema escolar. Assumindo-se, portanto, uma atitude de co-responsabilidade na formação do professor.

Finalmente, no estágio o aluno atua diretamente no ensino regular de Química. Para que o licenciando tenha vivência concreta do processo, torna-se necessária a adoção de mecanismos que lhe permitam o desempenho de todas as atividades pedagógicas inerentes ao processo educativo de uma turma específica, durante, pelo menos, um bimestre letivo. Isto significa que o estagiário é responsável direto pelo planejamento e desenvolvimento de todas as atividades educacionais, como aulas, exercícios, avaliações, anotações em diários de classe, participação em conselho de classe e demais atividades da escola. Para viabilizar tal estágio, a alternativa que se cogita é a adoção de estágios remunerados.

Além destas disciplinas, é exigido do aluno a realização de monografia de graduação na forma de projeto de ensino de Química, na qual se desenvolve uma proposta de ensino inovadora.

\section{e) Integração entre as diversas disciplinas no fluxo}

Adotou-se, como princípio para a organização curricular, a ausência de uma rede rígida de pré-requisitos, buscando-se desse modo viabilizar a flexibilidade que se antepõe ao "engessamento" do fluxo a ser seguido pelo aluno, sem, entretanto, perder de vista a relação conceitual, em termos hierárquicos, entre os programas das várias disciplinas. Sendo assim, não se estabeleceram blocos de disciplinas que sejam pré-requisitos de outro conjunto. Ao invés disso, fixou-se como prérequisito apenas a disciplina do núcleo conceitual envolvido.

Assim é que o fluxo inicia-se com a área de Química Inorgânica. No segundo semestre, introduz-se a área de Analítica, no terceiro, a de Orgânica e, no quarto, a de Físico-Química. Nessa sequiência, buscou-se a integração entre as disciplinas de uma mesma área e entre as áreas. Por exemplo, a disciplina introdutória de Química Inorgânica, antecede as demais áreas, em função de seu programa ter conceitos básicos para as mesmas. Por motivo semelhante, a última disciplina de Inorgânica vem após a quarta de Analítica, o mesmo ocorrendo em relação à seqüência das demais áreas.

A mesma integração foi feita entre as disciplinas de formação profissional docente. Tal formação inicia-se com uma disciplina ministrada pela Faculdade de Educação, depois passa pelas disciplinas do Instituto de Psicologia, retornando-se às disciplinas da Faculdade de Educação e terminando com as disciplinas de Ensino de Química e Estágio Supervisionado.

Buscou-se no fluxo, ainda, a distribuição de disciplinas de natureza prática e teórico-prática, de forma que o aluno sempre curse uma disciplina dessa natureza por semestre, garantindolhe uma vivência constante da experimentação, que é fundamental para o exercício do magistério de Química.

\section{DA ESTRUTURA DO CURRÍCULO}

A carga horária do curso é de 2760 horas, correspondendo a 184 créditos, sendo que os alunos terão que cursar disciplinas obrigatórias correspondentes a 2370 horas (158 créditos) e disciplinas optativas no total de 390 horas (26 créditos), conforme descrito no quadro 1.

A estrutura curricular dos cursos de graduação na UnB é 
Quadro 1. Carga horária do curso.

\begin{tabular}{lcc}
\hline Disciplinas & Total de créditos & Total de horas \\
\hline Obrigatórias & 154 & 2310 \\
Obrigatória Seletiva & 4 & 60 \\
Optativas & 18 & 270 \\
Módulo Livre & 8 & 120 \\
\hline TOTAL & 184 & 2760 \\
\hline
\end{tabular}

dividida em dois módulos: módulo integrante do curso e módulo livre. O módulo integrante do curso compreende o conjunto de disciplinas que assegura a formação acadêmica do profissional. Divide-se esse módulo em dois conjuntos de disciplinas: área de concentração e área de domínio conexo. As disciplinas da área de concentração do curso noturno de licenciatura em Química são as específicas de Química e as da formação profissional docente. As disciplinas da área de domínio conexo são as de outros cursos que têm afinidade com a Química e que complementam a formação do professor de Química (Matemática, Física, etc.)

As disciplinas do módulo integrante são classificadas em obrigatórias e optativas. As primeiras devem ser cursadas com aprovação para que o aluno integralize o seu currículo e conclua o curso. As disciplinas optativas são aquelas constantes no currículo que complementam a formação do licenciando, e que devem ser cursadas pelos alunos conforme o seu interesse. Algumas dessas disciplinas apresentam grande afinidade com o curso e, por isso, são consideradas como optativas recomendadas. Para a conclusão do curso, o aluno precisa cursar com aprovação disciplinas optativas cujo somatório de créditos corresponda ao total necessário para integralizar o currículo.

O módulo livre corresponde às disciplinas escolhidas livremente pelo aluno e que não integram o primeiro módulo de disciplinas. Tais disciplinas proporcionam o enriquecimento curricular por meio do contato do aluno com outros cursos e áreas do conhecimento. São considerados também como módulo livre os créditos conferidos por atividades de monitoria. O aluno poderá cursar até trinta e seis créditos em disciplinas deste módulo. No entanto, para fins de integralização da carga horária mínima exigida para a conclusão do curso, serão computados apenas oito créditos.

A distribuição de disciplinas por área do conhecimento é apresentada no quadro 2. Neste quadro, verifica-se que $49 \%$ das disciplinas obrigatórias são da área de química, $28 \%$ da área de formação profissional docente e $23 \%$ da área de Domínio Conexo (Matemática, Física, Biologia e Mineralogia).

No quadro 3 é apresentado o fluxograma do curso, no qual estão incluídas disciplinas obrigatórias e regularmente oferecidas para os alunos.

Quanto às optativas, existe uma relação de disciplinas dos sete cursos noturnos em funcionamento que podem ser cursadas pelos alunos. Estas disciplinas pertencem às áreas de concentração (Química e formação profissional docente) e às de domínio conexo (Matemática, Física, Psicologia, Geologia, Educação Física). Além dessas, existem as disciplinas do curso diurno, que os alunos podem cursar como optativas.

\section{CONSIDERAÇÕES FINAIS}

O currículo aqui apresentado foi aprovado pelo Conselho de Ensino, Pesquisa e Extensão -CEPE- da Universidade de Brasília em novembro de 1994. A sua implantação está sendo acompanhada e avaliada para que possam ser feitos os ajustes que se fizerem necessários.

Para acompanhar a implantação dos cursos noturnos de Licenciatura, o Decanato de Ensino de Graduação (DEG) instituiu Grupo de Trabalho das Licenciaturas com representantes de todos os cursos, a fim de discutir e aperfeiçoar os currículos aprovados. Este está desencadeando ações para garantir o planejamento integrado entre todas as disciplinas da formação profissional docente, que inclui disciplinas do Instituto de Psicologia, da Faculdade de Educação e, no nosso caso, do Departamento de Química.

Tais procedimentos, aliados aos descritos neste artigo, propiciam as condições para que os princípios curriculares aqui expostos sejam de fato incorporados na formação dos licenciandos.

Espera-se, com este projeto, enfrentar dois grandes desafios na formação de professores: a construção de uma identidade para o curso de licenciatura e a criação de oportunidades reais para a integração entre a formação específica (Química) e a pedagógica (domínio de ações que facilitem a aprendizagem).

Acreditamos que a estrutura curricular tradicional dos cursos de licenciatura, que polarizam a formação específica e a pedagógica, situando-as em espaços delimitados, sem que haja qualquer intercâmbio entre os mesmos (conhecimento químico: Instituto / Departamento de Química; conhecimento pedagógico: Instituto / Faculdade de Educação), pulverizam a formação do professor, gerando o despreparo do futuro profissional para desenvolver ações pedagógicas em sintonia com o conhecimento químico.

O desenvolvimento desta proposta procurou superar alguns

Quadro 2. Distribuição de disciplinas por área do curso.

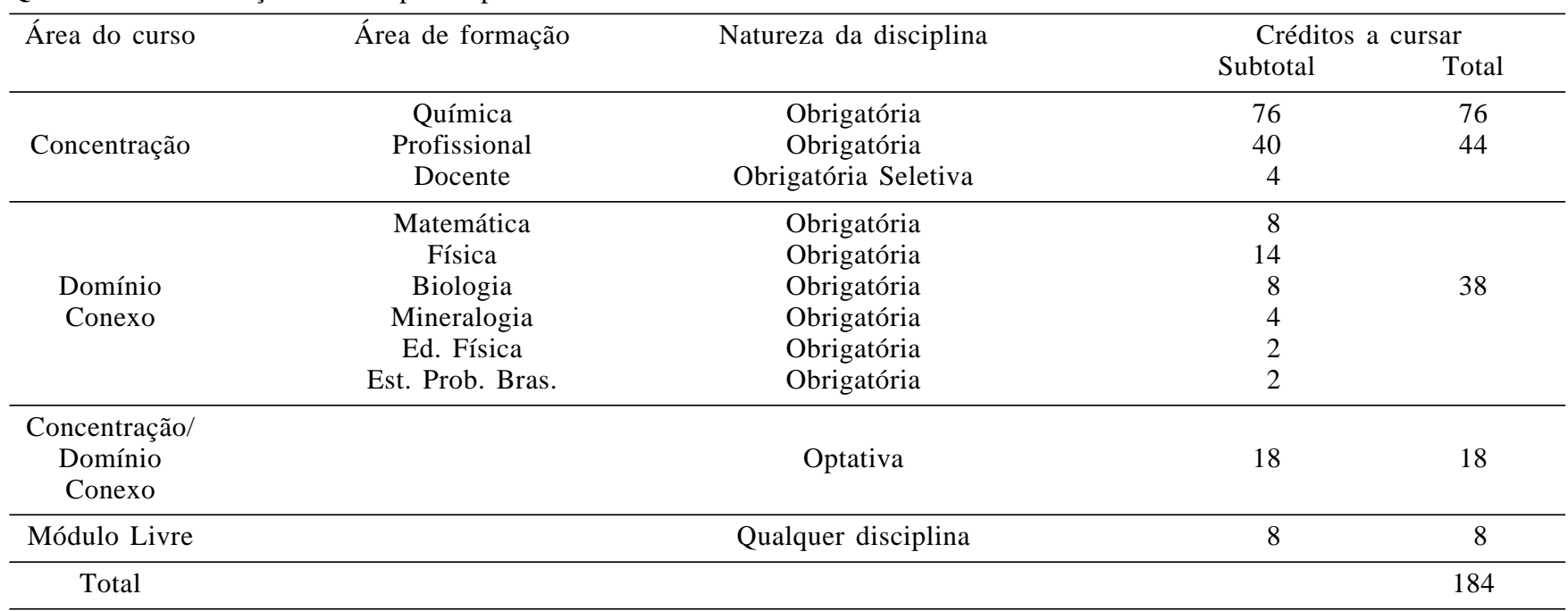


Quadro 3. Fluxo do curso recomendado por período letivo.

\begin{tabular}{|c|c|c|c|c|}
\hline Período & Disciplina & Natureza & Créditos & Pré-requisitos \\
\hline \multirow{6}{*}{1} & 1- Introdução ao Estudo da Química & OBR - T/P & 04 & \\
\hline & 2- Fundamentos de Química Inorgânica & OBR - T & 04 & \\
\hline & 3- Matemática 1 & OBR - T & 04 & \\
\hline & 4- Introdução à Microinformática & $\mathrm{OP}-\mathrm{T}$ & 04 & \\
\hline & 5- Introdução à Educação & $\mathrm{OP}-\mathrm{T}$ & 04 & \\
\hline & 6- Português Instrumental 1 & $\mathrm{OP}-\mathrm{T}$ & 04 & \\
\hline \multirow{6}{*}{2} & 7- Fundamentos de Química Analítica & OBR - T/P & 04 & 1 \\
\hline & 8- Química dos Elementos Representativos & $\mathrm{OBR}-\mathrm{T} / \mathrm{P}$ & 06 & 2 \\
\hline & 9- Matemática 2 & OBR - T & 04 & 3 \\
\hline & 10- Física 1 para Química & OBR - T & 04 & - \\
\hline & 11- Física Experimental para Química & OBR - P & 02 & - \\
\hline & 12- Organização da Educação Brasileira & OBR - T & 04 & - \\
\hline \multirow{5}{*}{3} & 13- Análise Química Qualitativa & $\mathrm{OBR}-\mathrm{T} / \mathrm{P}$ & 04 & 7 \\
\hline & 14- Fundamentos de Química Orgânica & OBR - T & 04 & 1,2 \\
\hline & 15- Física 2 para Química & OBR - T & 04 & $3,10,11$ \\
\hline & 16- Física 2 Experimental para Química & OBR - P & 04 & $3,10,11$ \\
\hline & 17- Desenvolvimento Psicológico e Ensino & OBR - T & 04 & - \\
\hline \multirow{5}{*}{4} & 18- Análise Química Quantitativa & OBR - T/P & 06 & 13 \\
\hline & 19- Reações Orgânicas e seus Mecanismos & OBR - T & 04 & 14 \\
\hline & 20- Termodinâmica Básica & OBR - T & 04 & 9,10 \\
\hline & 21- Aprendizagem no Ensino & $\mathrm{OS}-\mathrm{T}$ & 04 & - \\
\hline & 22- Inglês Instrumental 1 & $\mathrm{OP}-\mathrm{T}$ & 04 & - \\
\hline \multirow{5}{*}{5} & 23- Fundamentos de Análise Instrumental & $\mathrm{OBR}-\mathrm{T} / \mathrm{P}$ & 04 & 15,18 \\
\hline & 24- Química de Coordenação & OBR - T & 04 & 8 \\
\hline & 25- Equilíbrio Químico e Soluções & OBR - T & 06 & 20 \\
\hline & 26- Prática de Ensino de Química & OBR - P & 04 & - \\
\hline & 27- Didática Fundamental & OBR - T & 04 & 17 \\
\hline \multirow{5}{*}{6} & 28- Seminário de Química Orgânica & $\mathrm{OP}-\mathrm{T}$ & 02 & 19 \\
\hline & 29- Laboratório de Química Orgânica & OBR - T/P & 06 & 24 \\
\hline & 30- Estrutura de Átomos e Moléculas e Cinética Química & OBR - T & 04 & 25 \\
\hline & 31- Fundamentos de Mineralogia & OBR - T & 04 & - \\
\hline & 32- Ensino Médio de Química & OBR - T & 06 & $7,14,27$ \\
\hline \multirow{4}{*}{7} & 33- Tópicos de Química Ambiental & $\mathrm{OP}-\mathrm{T}$ & 04 & 14,18 \\
\hline & 34- Laboratório de Físico-Química & OBR - P & 04 & 25 \\
\hline & 35- Fundamentos de Bioquímica e Biofísica & OBR - T & 08 & 14 \\
\hline & 36- Materiais de Ensino de Química & $\mathrm{OBR}-\mathrm{T} / \mathrm{P}$ & 06 & 18,32 \\
\hline \multirow{5}{*}{8} & 37- Prática Desportiva & OBR - P & 02 & - \\
\hline & 38- Laboratório de Química Inorgânica Preparativa & $\mathrm{OP}-\mathrm{P}$ & 04 & 24 \\
\hline & 39- Introdução à Tecnologia Química & OBR - T/P & 04 & 13,14 \\
\hline & 40- Evolução dos Conceitos de Química & OBR - T & 04 & $7,14,20$ \\
\hline & 41- Tópicos de Ensino de Química & $\mathrm{OP}-\mathrm{T}$ & 04 & 36 \\
\hline \multirow[t]{2}{*}{9} & 42- Projeto de Ensino de Química & OBR - T & 02 & 36 \\
\hline & 43- Estágio em Ensino de Química & OBR - P & 10 & 26,36 \\
\hline
\end{tabular}

Legenda: OBR - Obrigatória; T - Disc. Teórica; OP - Optativa; P - Disc. Experimental; OS - Obrigatória Seletiva; T/P - Disc. Teórica/Experimental.

desafios já existentes e certamente criará outros; o fortalecimento da área de ensino de química será, sem sombra de dúvida, um caminho para suplantá-los, conforme salientado por Schnetzler ${ }^{19}$. Um outro grande desafio será o de conscientizar o corpo docente do curso que formar professor de química é assumir um compromisso com a sociedade na árdua tarefa de educar seus cidadãos.

\section{REFERÊNCIAS}

1. Pinto A. G. de T. (org.); Os cursos noturnos de licenciatura: um projeto acadêmico orgânico para a Universidade de Brasília; Universidade de Brasília / Decanato de Ensino de Graduação; Brasília, 1993.
2. Candau, V. M. F. (Coord.); Novos rumos da licenciatura; INEP: Pontifícia Universidade Católica do Rio de Janeiro; Brasília, 1987.

3. Gil-Pérez, D.; Carvalho, A. M. P.; Formação de professores de ciências; tendências e inovações; Cortez, São Paulo, 1993.

4. Linhares, C. F. S.; In: Formação de Professores; pensar e fazer; Alves, N. (org.), Cortez, São Paulo, 1993; p. 9.

5. Moereira, A. F.B.; In: Formação de Professores; pensar e fazer; Alves, N. (org.); Cortez, São Paulo, 1994; p. 73.

6. Astolfi, Jean-Pierre; Develay, M.; A didática das ciências; Papirus, Campinas, 1990.

7. Moreira, M. A.; Em aberto 1989, 40, 43. 
8. Gauche, R.; Dissertação de Mestrado; Universidade Estadual de Campinas, Campinas, 1992.

9. Santos, L., L. de C. P.; Revista Brasileira de Estudos Pedagógicos 1991, 72, 318.

10. Harley, W.; Osborne, R.; Journal of Curriculum Studies 1985, 17, 133.

11. Pimenta, S. G.; O estágio na formação de professores; unidade, teoria e prática?; Cortez, São Paulo, 1994.

12. Alves, N.; Garcia, R. L.; In: Formação de Professores; pensar e fazer; Alves, N. (org.); Cortez, São Paulo, 1993; p. 73.

13. Morosini, M. S.; Tese de Doutorado; Universidade Federal do Rio Grande do Sul; Porto Alegre, 1990.
14. Tunes, E. Aprender a ensinar é aprender para ensinar. Anais da XXI Reunião Anual de Psicologia; Sociedade de Psicologia de Ribeirão Preto, 1991, p. 41.

15. Ausubel, D. P.; Education psychology: a cognitive view. (1 ed) New York, Holt, Rinehart and Winston, 1968.

16. Bybee, R. W.; Mau, T.; Journal of Research in Science Teaching 1986, 23, 599.

17. Fenshan, P. J.; International Journal of Science Education 1988, $10,346$.

18. Santos, W. L. P.; Dissertação de Mestrado; Universidade Estadual de Campinas, Campinas, 1992.

19. Schnetzler, R. P.; Aragão. R. M. R.; Química Nova na Escola 1995, 1, 27. 